\title{
Why many doctors still find it difficult to talk about dying with patients
}

\author{
- Cite as: CMAJ 2019 January 7;191:E22-3. doi: 10.1503/cmaj.109-5691
}

Posted on cmajnews.com on Dec. 4, 2018.

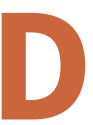

eath is the ultimate inconvenient truth, its inevitability a conversation that far too many doctors still go out of their way to avoid, according to a recent report by Britain's Royal College of Physicians. Talking about dying: How to begin honest conversations about what lies ahead looks at why doctors and other health care professionals find it so difficult to talk about dying to patients who are frail or terminally ill. Everyone realizes that early and honest conversations allow both doctors and patients to better explore the choices around their future care. So why isn't it happening as often as it should?

The report cites three barriers identified by doctors. Some struggle with the limitations of medicine, perceiving death as failure, while others feel ill-equipped to initiate the conversation. The final barrier was of a more practical nature: confusion over which of the patient's caregivers should take the lead in opening a dialogue.

But Kathy Kortes-Miller says talking about death and dying should be a twoway street. "As recipients of care, we also need to build up our own abilities on the topic and let our health care providers know that we are willing to have that conversation," she says. The palliative care division lead at Lakehead University's Centre for Education and Research on Aging and Health, she wrote Talking About Death Won't Kill You: The Essential Guide to End-of-Life Conversations after realizing how difficult it was to discuss her own fears with her surgeon after a cancer diagnosis a decade ago.

As for health care professionals, they also need to learn how to take the initiative when end-of-life conversations are needed. "If physicians can grow their capacity to have these conversations, they will increase their feeling of connection with some of the people they're serving. It will ultimately help their jobs be more rewarding and meaningful for them."

That's a view echoed by Dr. Leonie Herx, president of the Canadian Society of Palliative Care Physicians. She notes that beings who live and die," she explains. "We need to normalize dying and death as part of life. We need to use the D words."

Herx says discussing the possibility of deterioration and death should be part of a standardized approach to providing care and options for treatment once a patient is diagnosed with a life-

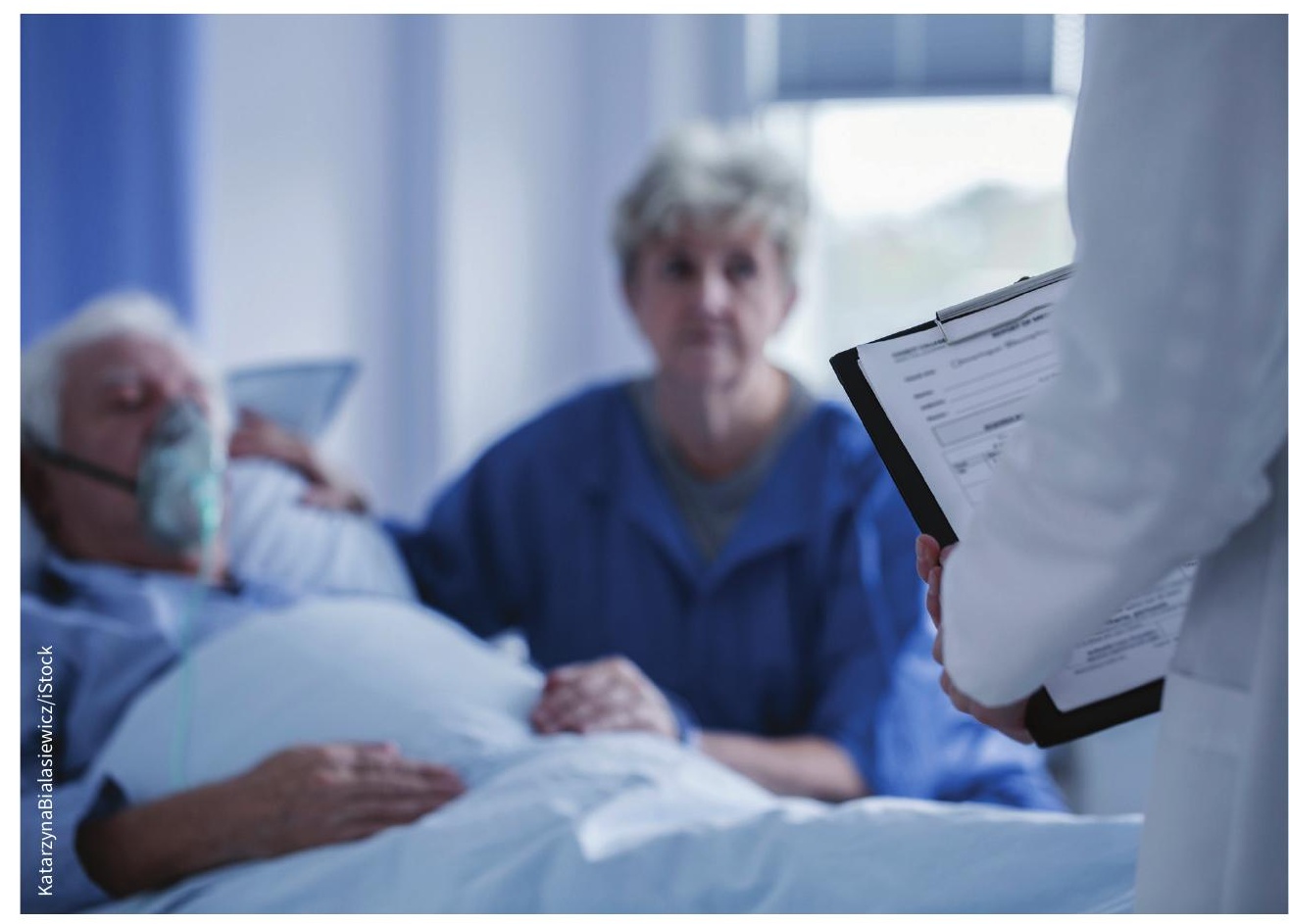

Early and honest conversations about death allow doctors and patients to better explore choices around future care.

medicine is realizing the importance of teaching communication skills and normalizing "serious illness conversations" with patients. Like Kortes-Miller, she advocates for a cultural shift that encompasses both health care professionals and society in general. "Yes, modern medicine can do amazing things, but we are all human threatening illness. Having that talk sooner rather than later also gives the individual and their family time to discuss the "what ifs" before they occur. "These conversations can happen at the same time as maintaining hope for cure or control of disease," says Herx. "It can be a normal part of helping a patient 
and family understand and prepare for all of the possibilities."

More palliative care education is also key to making substantive change happen, according to Dr. Susan MacDonald, an associate professor of family medicine at Memorial University. She begins formal teaching sessions about palliative care with medical learners in their first year, but it's also crucial to reach people outside of university and hospital settings.
"We take the LEAP program [Learning Essentials in Palliative and End of Life Care] on the road across the province," MacDonald explains. She offers the two-day learning course to family physicians, hospitalists, nurses, social workers and volunteers. Kortes-Miller also takes her knowledge on the road, educating frontline workers in long-term care facilities, hosting community talks, and working with Indigenous communities in Ontario to help them build capacity for caring for people at end of life.
It all comes down to making people comfortable with the idea that death and dying are normal, natural parts of life. Even physicians must face the uncomfortable truth that not every condition is curable. "I've seen many physicians cling to very unrealistic ideas long after any chance to see those ideas work," says MacDonald. "Why? Because they don't know how to deal with the alternative."

Sarah Brown, Ottawa, Ont. 